\section{"FUNCTIONAL" DISORDERS}

\section{A FOLLOW-UP STUDY OF OUT-PATIENT DIAGNOSIS}

BY

H. JACOBS, M.B., B.Sc., M.Med., M.R.C.P.Ed. AND

\section{W. RITCHIE RUSSELL, C.B.E., M.D., D.Sc. F.R.C.P.}

(Department of Neurology, United Oxford Hospitals)

Every physician and surgeon is aware that in a large proportion of hospital out-patients he will find no evidence of organic physical disease, while the nature of the symptoms is such as to make it probable that psychogenic or stress factors are chiefly responsible for the clinical picture. All clinical consultants are concerned with this problem, for many patients are referred for an opinion concerning symptoms which might at first sight be either organic or functional in origin.

There are many difficult aspects of this problem. In the first place there is the ever-present danger of being unduly influenced by the patient's personality, for it is easy to be misled by an attitude of anxiety, hysteria, hypochondriasis, or depression. On the other hand, every specialist should endeavour to correct anxiety states and minor psychiatric reactions connected with his own specialty that are referred to him for advice. His knowledge of relevant organic disease makes it easier for him than for anyone else to correct unreasonable fears and adjust problems of living which are having a harmful effect. The consultant, therefore, must make the diagnosis and should usually also provide the treatment for his cases of functional disorder, for it is undesirable to bring in another specialist when simple and authoritative reassurance is what is chiefly needed.

In certain cases the consultant has a faint reservation that organic disease is developing; yet he should reassure dogmatically so as to find out how much good this will do-as a therapeutic test-and then it is best to see the patient after an interval to ensure whether reassessment is required.

There is no limit to the number of investigations that can be carried out, and with every out-patient a decision must be taken on whether special investigations are indicated.

Many patients have some minor form of organic disease to which they have reacted to an excessive degree, and in these the apparent disability may be out of all proportion to the degree of organic change. In such a situation a few words of explanation may have a dramatic effect in improving the clinical picture and the mental outlook of the patient. The reaction of the individual to symptoms requires to be studied just as much as. the disease itself, but there is rarely time to investigate this in detail. In practice, it is informative to observe the patient's reaction to the comment made after examination, such as "there is no serious disease ; I think we can get you much better." Some display such astonished relief that one can only conclude that they felt themselves to be under sentence of death or disablement. Others respond, "Oh, of course I know there is nothing to worry about," and from this one may sometimes conclude that the symptoms described are worse than the patient has indicated. Included in this group are what may be described as the "intellectuals," whose clinical story is so mixed up with their own theories of causation and mechanism that one comes to doubt the advantages of education!

In connexion with this problem it is of interest to assess the accuracy of diagnosis in a neurological outpatient clinic in a general hospital. In this study patients have been followed up who, when seen as out-patients, were thought to have negligible organic disorder but a large functional factor in their disability.

The purpose of this study, therefore, is to ascertain whether the opinion formed regarding the absence of organic disease was correct and to what extent the reassurance and advice given was effective.

\section{Method of Study}

The Oxford neurological out-patient clinic at one hospital has about 1,000 new cases referred to it each year. The patients chosen for this study were nearly all seen during the years 1954 and 1955 by the two consultants then available, who were often obliged each to see 10 or 12 new cases in the space of two and a half hours. The usual plan was for the consultant to take the history from the patient, and in many cases he would then delegate part of the examination to a registrar. In all instances he would, after reassessment had been completed, give a few words of explanation to the patient and, where indicated, would attempt to give necessary reassurance, such as: "We are quite sure there is no serious trouble. I shall write to your doctor, and if you are not better soon we shall see you again." These simple words are designed to make the patient feel he has sympathetic access to specialist advice in the future as well as to relieve his main fears for the present. Provision for the future is, after all, an important aspect of personal morale.

In order to assess the value of this procedure a consecutive series of the out-patient records was studied and 100 records were extracted in which the consultant concerned decided that the presenting symptoms were, so far as he could judge, not due to organic disease of any importance. This opinion was generally based on a study of the symptoms and signs only, but in 36 cases some special investigation was carried out, such as E.E.G., $x$-ray examination of the skull, neck or chest, or Wassermann reaction.

There is a constant problem regarding the need for further investigation, and some experience is needed for making the decision against an elaborate series of tests. For this reason out-patients should be seen by the most experienced specialists available.

\section{Analysis of Symptoms}

This study is therefore concerned with 100 patients who were thought to have no significant organic disease, and who received little treatment from the department other than reassurance and advice regarding any circumstances in their lives which might be causing stress. This group represented about $5 \%$ of the outpatients seen in this clinic during 1954 and 1955.

The group comprised 46 males and 54 females; 67 were married, 24 single, 3 widowed, and 2 divorced; the status of 4 was not known. As regards occupation, 44 were housewives, 18 were professional, 13 were 
skilled, 17 semi-skilled, and 6 unskilled workers, and 8 (including 6 housewives) were in other categories.

The age distribution was as follows: Under 20, 7 ; $20-29,18 ; 30-39,27 ; 40-49,34 ; 50-59,8 ; 60+, 6$.

The season of attendance was January-March in 13, April-June in 25, July-September in 27; and OctoberDecember in 35.

Consultant A saw 52, consultant B 42, and another consultant 6. Specialist advice regarding the same symptoms had previously been given to 40 .

The diagnosis accompanying the patient (from practitioner or specialist) was organic in 43 ; psychogenic in 15 ; both organic and functional in 5 . None was offered in 37 cases.

The patients studied presented a great variety of symptoms. Many of these suggested some minor physical disorder which, however, had become built into a collection of symptoms that led to a somewhat confusing picture. The consultant's view in all instances was that most of the apparent disability was caused by psychogenic factors.

Some of the symptoms complained of, and the clinical features, may be listed as follows ( $88 \mathrm{had}$ more than one complaint or symptom):
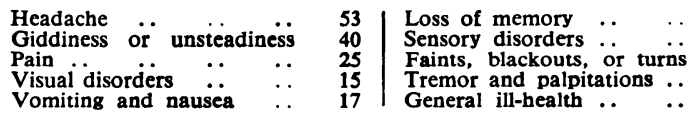

Contributing factors mentioned were: fatigue and overwork in 25 ; domestic stress and children in 29 ; and insomnia, depression, and anxiety in 39.

The presenting symptoms varied greatly, and the following case summaries illustrate the type of case under consideration.

\section{Case Reports}

Case I.-A 43-year-old housewife was referred by a general practitioner because of a history of "fainting" which occurred at times of emotional stress. At the neurological out-patient clinic she stated that the "faints" were associated with a feeling of shortness of breath. In addition, she stated that the attacks occurred often when she stood up suddenly. On examination her blood-pressure was $140 / 90$ and the cardiovascular and nervous systems were normal. It was thought that this patient's symptoms were associated with frightening emotional reactions and seemed to some extent to be postural. It was also clear that she had been overworking as well as having a considerable amount of domestic stress. She was dogmatically reassured that she had no organic disease and was advised to try to take a holiday or to rest at frequent intervals. Six years later the general practitioner wrote: "No organic disease has developed since you saw her."

Case 11.-A 49-year-old housewife was sent up by a general practitioner with a history of one or two "turns" over the past few months. He was puzzled by the appearance of her right optic disk, and as he considered her not to be a neurotic woman he wondered about the possibility of early neurological disease. At the neurological outpatient clinic she gave a vague history of "turns" which were not associated with loss of consciousness. On questioning she stated she had had considerable domestic troubles. On examination opaque nerve fibres were seen in her right fundus, but there were no other abnormal signs in the central nervous system. It was thought that the episodes were due to a combination of worry and fatigue. She was reassured that she had no organic illness. Six years later the general practitioner wrote: "To all intents and purposes this patient is fit and well."
Case III.-A 35-year-old housewife was referred by a general practitioner because of "attacks of giddiness" and a vague unpleasant sensation in the epigastrium which involved also the back of her neck and spread down to the back of her legs. She had "no use of her legs" in the mornings. The general practitioner asked for an opinion on the possibility of - neurological disease and, if none was found, whether she should be referred to a psychiatrist. At the neurological out-patient clinic she gave a history of having felt generally unsteady for the past six months, which was accentuated by worry. She also complained of tearfulness, sleeplessness, and depression. Physical examination revealed nothing abnormal. She was anxious and tense, with a state of mild panic, and it was thought that the whole condition was psychogenic. She was reassured and given a sedative. In a letter to her general practitioner this opinion was given, and, in answer to her specific query, psychiatric help was advised if the simple measures advocated did not improve her symptoms. Six years later the general practitioner wrote that he had just been to see this patient and found her “ in fairly good health-still 'nervy,' but generally much better than when seen at the neurological clinic. There was no suspicion of organic disease."

Case IV.-A 28-year-old woman was referred by a general practitioner because she complained of a drooping left eyelid which had obscured the vision in that eye for the previous five months. It was stated that she had been to see an ophthalmic surgeon but that " he had been unable to help." On examination at the out-patient clinic there was no sign of the lid drooping, but she expressed fear that she was going blind. She was told there was no impairment of vision and no risk of her losing her sight. Six years later the patient wrote: "I have had no illness since I attended at the neurological department."

Case V.-A 44-year-old man, an assistant secretary to a mental home, was referred by a general practitioner because of left-sided dull headache which had been present for the past year. The pain was relieved by aspirin. He was sent for "diagnosis and treatment." On examination at the neurological clinic no abnormal signs were found. It was thought that his headache was psychogenically determined, and that it was associated with a period of increased anxiety and stress. He was reassured and given a sedative. Six years later his doctor reported: "I think this man's illness was psychogenic in origin; he has remained in excellent physical and mental health since you saw him."

Case VI.-A 63-year-old head gamekeeper was referred by a general practitioner for opinion because of a two-year history of pins-and-needles in the right foot. The referring doctor found some sensory disturbance in the foot. At the neurological clinic the history he gave was of acute nocturnal cramp-like pain in his foot which forced him to get out of bed and use the foot to ease the pain. He also said that there was "paralysis in my family." On examination there were no abnormal physical signs. It was thought that he had a variety of muscle cramp which was of no special significance and he was reassured that he had no organic disease. Six years later the general practitioner wrote: "This man is well. No organic disease has developed since you examined him."

\section{Follow-up Study}

In the follow-up study eight patients had left the district and could not be traced. Of these eight, 3, 2 , and 3 were respectively in the age groups $20-29$, $30-39$, and $40-49$ years.

The other 92 patients were traced. The follow-up period was 4 to 6 years in 80 cases, 2 to 4 years in 6 , and 1 to 2 years in $6 ; 78$ were in good health, but in 26 of these some minor symptoms persisted though they were not disabling. Fourteen of the patients were reported to have developed some organic disorder, which in five instances was probably related to the 
Details of 14 Patients Who Developed Some Organic Disorder

\begin{tabular}{|c|c|c|c|c|}
\hline \multirow{2}{*}{$\begin{array}{c}\text { Case } \\
\text { No. }\end{array}$} & \multicolumn{2}{|c|}{$\begin{array}{c}\text { Sex } \\
\text { and Age }\end{array}$} & $\begin{array}{l}\text { Presenting } \\
\text { Symptoms }\end{array}$ & Follow-up \\
\hline & $\mathbf{F}$ & 57 & $\begin{array}{l}\text { Weakness and paraesthe- } \\
\text { siae. Bizarre gait but } \\
\text { organic signs doubtful. } \\
\text { Gait thought to be } \\
\text { "largely functional" }\end{array}$ & $\begin{array}{l}\text { Developed disseminated } \\
\text { sclerosis and died in } \\
2 \frac{1}{2} \text { years }\end{array}$ \\
\hline 2 & $\mathbf{M}$ & 46 & $\begin{array}{l}\text { A Polish refugee with recur- } \\
\text { ring chest pain. Neurotic } \\
\text { history }\end{array}$ & $\begin{array}{l}\text { Died of carcinoma of } \\
\text { stomach } 2 \frac{1}{2} \text { years later }\end{array}$ \\
\hline 3 & $\mathbf{M}$ & 47 & $\begin{array}{l}\text { Feelings of unsteadiness } \\
\text { associated with concen- } \\
\text { tration or anxiety }\end{array}$ & $\begin{array}{l}5 \text { years later-“" has odd } \\
\text { fits at night," probably } \\
\text { epileptic }\end{array}$ \\
\hline 4 & $\mathbf{F}$ & 34 & $\begin{array}{l}\text { Dizzy spells. Sudden short- } \\
\text { ness of breath and every- } \\
\text { thing goes black. Some } \\
\text { E.E.G. instability }\end{array}$ & $\begin{array}{l}\text { Thought to have epileptic } \\
\text { fits } 4 \text { years later }\end{array}$ \\
\hline 5 & $\mathbf{F}$ & 21 & $\begin{array}{l}\text { Episodes of left scalp and } \\
\text { face pain which occurred } \\
\text { between } 5 \text { and } 6 \text { p.m. } \\
\text { every day. Third molars } \\
\text { erupting. Anxious }\end{array}$ & $\begin{array}{l}\text { Developed abscesses at } \\
\text { roots of } 2 \text { molar teeth } \\
\text { several months later. } \\
\text { Pain relieved by extrac- } \\
\text { tion of teeth }\end{array}$ \\
\hline 6 & $\mathbf{M}$ & 45 & $\begin{array}{l}\text { Recurrent left-sided head- } \\
\text { ache, probably subocci- } \\
\text { pital in origin. } \\
165 / 105\end{array}$ & $\begin{array}{c}\text { Developed systemic hyper- } \\
\text { tension followed by } \\
\text { cerebral thrombosis } \\
\text { from which he had made } \\
\text { a good recovery } 6 \text { years } \\
\text { later }\end{array}$ \\
\hline 7 & M & 49 & $\begin{array}{l}\text { Dull continuous frontal } \\
\text { headache }\end{array}$ & $\begin{array}{l}\text { Developed myxoedema } \\
\text { and anaemia } 2 \text { years } \\
\text { later }\end{array}$ \\
\hline 8 & $\mathbf{M}$ & 48 & $\begin{array}{l}\text { Inability to move lower } \\
\text { limbs } 6 \text { months after a } \\
\text { minor fall while at work, } \\
\text { having worked for several } \\
\text { months immediately after } \\
\text { accident., "Traumatic } \\
\text { neurosis" }\end{array}$ & $\begin{array}{l}\text { G.P. wrote } 6 \text { years later: } \\
\text { "Condition unchanged; } \\
\text { wears a surgical corset" }\end{array}$ \\
\hline 9 & $\mathrm{~F}$ & 34 & $\begin{array}{l}\text { Recurrent headaches asso- } \\
\text { ciated with concentration }\end{array}$ & $\begin{array}{l}\text { Had severe gastro-intes- } \\
\text { tinal haemorrhage } 6 \\
\text { years later. No further } \\
\text { headache }\end{array}$ \\
\hline 10 & $\mathbf{M}$ & 33 & Frontal headache for 2 years & $\begin{array}{l}\text { Developed pulmonary le- } \\
\text { sion as yet undiagnosed } \\
\text { at end of } 6 \text {-year period }\end{array}$ \\
\hline 11 & $F$ & 43 & 8-year history of headache & $\begin{array}{l}\text { Total hysterectomy for } \\
\text { fibroids } 6 \text { years later }\end{array}$ \\
\hline 12 & $\mathbf{F}$ & 43 & "Faints" and sweating & $\begin{array}{l}\text { Developed brachial neuri- } \\
\text { tis } 6 \text { years later. Some } \\
\text { nervous symptoms asso- } \\
\text { ciated with marital diff- } \\
\text { culties }\end{array}$ \\
\hline 13 & $F$ & 19 & $\begin{array}{l}\text { Attacks of tiredness and } \\
\text { nausea }\end{array}$ & $\begin{array}{l}\text { Developed fibroids and } \\
\text { menorrhagia } 6 \text { years } \\
\text { later. Benign nodule in } \\
\text { left breast removed }\end{array}$ \\
\hline 14 & $\mathbf{M}$ & 27 & "Fainting turns" & $\begin{array}{l}2 \text { years later developed } \\
\text { erythema nodosum and } \\
\text { raised E.S.R. thought to } \\
\text { be related to chest } \\
\text { disease. No fainting } \\
\text { turns. 6 years later in } \\
\text { good health }\end{array}$ \\
\hline
\end{tabular}

original presenting symptoms. Some particulars of all 14 cases are given in the Table: further particulars of the first two cases are as follows:

Case 1.-A 57-year-old woman was referred from the medical wards of another general hospital. She gave a history of progressive weakness of all limbs for two months prior to admission. For one month she had had paraethesiae in the soles of her feet. At the time of admission she was unable to stand, dress herself, or eat without assistance. There was no speech, visual, or bladder disturbance. Examination revealed a mentally dull patient with minimal weakness in the upper limbs and some weakness of the dorsiflexors of the left foot. There was slight ataxia in the upper limbs. A large number of investigations were done, all of which were normal, except for a blood urea of $78 \mathrm{mg} . / 100 \mathrm{ml}$. The blood and cerebrospinal fluid were normal. She had been seen by a psychiatrist, who found no mental or emotional disorder. A second neurological examination after one month was normal. At the neurological out-patient clinic her low intelligence was confirmed. There was no convincing weakness of the limbs ; and the disability was thought to be out of all proportion to the slight organic signs. Vigorous encouragement was advocated to see how far she would improve, with the comment that further study would be necessary if progress was not satisfactory. She was not seen again, and on follow-up was reported to have died. two and a half years after being seen, of a disease of the spinal cord thought to be disseminated sclerosis, but a postmortem examination was not carried out.

Case 2.-A 46-year-old Polish man was referred by the medical officer at a Polish hostel because he was suffering from "general neurosis" and had a variety of pains in his chest. An examination and opinion were requested. At the neurological out-patient department the patient stated that he had had intermittent left-sided chest pain for the past two months. One year ago he had had a similar episode which had spontaneously resolved. In addition, he complained of acid eructations. On examination he appeared to be in excellent physical condition and there were no abnormal signs apart from an old injury to his right eye. A chest $x$-ray film taken at this time showed nothing abnormal. It was thought that he was suffering from a mild anxiety state superimposed on a chronic dyspepsia. He was advised to modify his diet and to take regular alkalis, and was reassured that he had no serious disease. Two and a half years later he died in another hospital of carcinoma of the stomach.

\section{Discussion}

More than 60 of these 100 patients were aged from 30 to 49 , and there is little doubt that the stresses of their environment, with some anxiety and depression, contributed to their illness. The season at which the consultation took place seems to have some bearing on the figures-the highest (34) was in the last quarter of the year and the lowest (13) from January to March. All cases were referred to the department with the idea that physical disease might be present, and in 43 of the patients there was a tentative organic diagnosis.

The follow-up inquiry was specially directed towards the presence of organic disease, and the findings indicate that organic disease was only rarely overlooked. Our experience is, however, at variance with that of some others. Thus Comroe (1936) followed up 100 patients discharged from a general medical ward with the diagnosis of neurosis, and found that $24 \%$ had developed organic disease within eight months. Marshall (1949) studied 175 patients who had been admitted to the wards of a psychiatric unit, all of whom were in need of psychiatric treatment. In $77(44 \%)$ some physical condition needing attention was discovered. Similarly, Herridge (1960) was impressed by the number of "purely physical" conditions initially diagnosed as "functional." He found 11 patients $(5 \%)$ with major physical disease among those who had been referred as having functional illness. In a further 43 (21\%) he found that physical conditions (of marked severity in many cases) had contributed to the onset of psychological illness.

The follow-up study presented here indicates a much higher degree of accuracy in distinguishing the organic from the functional, but, even so, mistakes have occurred, and every effort is required to reduce the margin of error.

There seems to be little doubt that follow-up studies of this kind will improve the standard of out-patient diagnosis, and should be widely practised.

\section{Therapeutic Effects}

This study was primarily concerned with the problem of the difficulty of recognizing organic disease in neurotic patients. However, the attitude of the consultant at the time of the out-patient interview is as much concerned with treatment as with diagnosis. Thus he endeavours to exclude organic disease and also to 
do what he can to correct anxiety and the more obvious environmental factors which may be contributing to the symptoms.

The impression from the follow-up reports of the functional cases is that both physical and mental health have been quite good during the years that followed consultation and that the reassurance provided at the clinic was in many instances justified by the course of events. We have no means of determining accurately the benefit to mental health which accrued from the advice given at consultation, and have relied-as others have-on the reports of the patient's personal medical attendant. In this suries the generally good prognosis in neurosis is in accordance with the findings of others.

Eysenck (1952), while surveying the effects of psychotherapy, came to the conclusion that there was little to support the hypothesis that psychotherapy facilitated recovery in neurotic patients. Nevertheless, the role of the doctor as a therapeutic agent is well recognized, and this aspect has been studied and emphasized by Wolf (1959) and by Hankoff et al. (1960).

Our impression, therefore, is that the psychological effect of a properly conducted out-patient examination can be very valuable and is worthy of special study.

\section{Summary}

About $5 \%$ of out-patients attending a neurological clinic were thought by the consultants concerned to have no significant organic disease to account for their symptoms. A series of 100 of these " functional " cases, which had been treated chiefly by reassurance and explanation, were followed up over five years later.

Eight had left the district and could not be traced. Of the remaining 92,78 were in good health and had no apparent organic disease, but in 26 of these some minor symptoms persisted although these were not disabling.

Two patients died two and a half years after being seen-one of carcinoma of the stomach and one with disseminated sclerosis. Two patients developed epilepsy, one had a facial pain later relieved by tooth extraction, one developed hypertension, one developed myxoedema, and one developed a prolapsed disk.

Six patients developed organic illness which had no obvious connexion with the original presenting symptoms.

It is suggested that consultants should in most instances endeavour themselves to treat the functional cases attending their clinics and that by conducting follow-up studies they can check on the standard of work.

It seems desirable that the most experienced personnel available should work in the out-patient departments of hospitals.

ADDENDUM.-Since preparation of the paper two further patients have been traced. Both have remained in very good health at the end of a five-year follow-up.

\section{REFERENCES}

Comroe, B. I. (1936). J. nerv. ment. Dis., 83, 679.

Eysenck, H. J. (1952). J. con. Psychol., 16, 319.

Hankoff, L. D., Engelhardt, D. M., and Freedman, N. (1960). Arch. gen. Psychiat., 2, 33.

Herridge, C. F. (1960). Lancet, $2,949$.

Marshall, H. E. S. (1949). Brit. med. J., 2, 468.

Wolf, S. (1959). Ass. Res. nerv. Dis. Proc., 37, 147.

\section{TWO GENERATIONS OF BROKEN HOMES IN THE GENESIS OF CONDUCT AND BEHAVIOUR DISORDERS IN CHILDHOOD}

BY

\section{J. WARDLE, M.D., D.P.M.}

Consultant in Child Psychiatry for North Lincolnshire; Formerly Registrar, Bethlem Royal and the Maudsley Hospitals

Many reports have demonstrated that the proportion of delinquent children that come from "broken homes" is higher than would be expected by chance, though Wootton (1959) has noted that this is not a universal finding-for example, Ferguson (1952)-and points out the lack of uniformity of definition of " broken homes" in the reports and the difficulty of obtaining a satisfactory control population. A similar high proportion of children from broken homes has been found among children defined as maladjusted-for example, Banister and Ravden (1944, 1945) and Burt and Howard (1952). Among maladjusted children there appears to be an association between the type of symptoms the child presents and the type of home environment. In the study of Banister and Ravden, the proportions of children from broken homes were $81 \%$ of 27 delinquent children, $42 \%$ of 31 aggressive children, $22 \%$ of 41 nervous children, and $8 \%$ of 13 backward children. Of 93 children from the same schools who were regarded as normal, only $13 \%$ were from broken homes.

Separation from mother during early childhood has been thought to be of major importance in the genesis of delinquency - for example, Bowlby (1944)-and, since separation from mother is more likely to have occurred in a broken home than in an intact one, separation might be the operative factor in the genesis of delinquency in children from broken homes.

The importance of specific parental attitudes and child-rearing practice in the genesis of specific types of disordered behaviour has long been recognized (Cameron, 1919; Kanner, 1957). Valuable evidence has recently been presented about the relationship of particular behavioural characteristics in young children to particular parental attitudes and methods of childrearing (Sears et al., 1957). Sears found that parents who love and accept their children and use withdrawal of approval as a technique of discipline rather than bribery or physical punishment produced the highest percentage of children rated as having a conscience; these parents also tended to produce a higher proportion of dependent children. Cold punitive mothers produced the lowest proportion of children with a conscience.

Sears also found that aggressiveness in children was associated with inconsistent punitive methods of discipline and occurred in families where aggression was often expressed by the parents but punished physically if it occurred in the child. The mothers of aggressive children and of children with poorly developed consciences tended to lack warmth for their children and to be more punitive; both these characteristics were associated with a low self-esteem, a tendency to be dissatisfied with their lot and with the maternal role, a poor opinion of their husband, and a tendency to disagree with their husband over the 